\title{
Burden Of Treatment Among Patients Undergoing Intravitreal Injections For Diabetic Macular Oedema In Australia
}

This article was published in the following Dove Press journal: Diabetes, Metabolic Syndrome and Obesity: Targets and Therapy

\author{
Kimberly L Spooner $\mathbb{D}^{1,2}$ \\ Gerry Guinan ${ }^{3}$ \\ Saskia Koller ${ }^{3}$ \\ Thomas Hong' \\ Andrew A Chang ${ }^{1,2}$ \\ 'Sydney Institute of Vision Science, \\ Sydney Retina Clinic, Sydney, NSW, \\ Australia; ${ }^{2}$ Save Sight Institute, University \\ of Sydney, Sydney, NSW, Australia; ${ }^{3}$ So \\ What Research, Pty Ltd, Sydney, NSW, \\ Australia
}

\begin{abstract}
Aim: The incidence and prevalence of diabetes mellitus (DM) in Australia is increasing. Thus, it is essential that practitioners appreciate the impending effect that increasing incidence of diabetes has on patients and the wider community. Accordingly, this study examines the humanistic burden of intravitreal injections for the treatment of diabetic macular oedema (DMO) among several health variables.
\end{abstract}

Methods: Survey data from a representative sample of Australian adults undergoing treatment for DMO were examined. Respondents participated via an online survey recruited by means of a national online consumer panel and the New South Wales and Victorian Diabetes Foundations. The online survey included questions relating to the humanistic burden of disease, such as the emotional and physical impact of intravitreal injection therapy; the practical impacts of injection therapy; and to identify potential improvements to treatment regimens.

Results: Sixty-five participants took part in the online survey. Of these, $49 \%$ had their most recent injection $<1$ month prior to completing the survey. The mean age was 52.5 years, with the majority of patients in full-time work. A substantial proportion of participants had several comorbidities, with a significantly high Charlson comorbidity index of 2.7. Participants reported the main burden of DMO care was the direct cost of medical treatment and the time burden demanded upon their carers. Results suggest that the overall burden is significant for those with diabetes and increases as additional complications of diabetes occur.

Conclusion: These results suggest that treatment strategies for DMO should consider clinical, humanistic and economic burden and patients should be educated on the roles of complications in disease outcomes. Less frequent treatment regimens could also reduce the economic burden and assist in decreasing the effect on health care resources, relevant to the escalation in the prevalence of diabetes.

Keywords: diabetes, macular oedema, intravitreal injections, anti-VEGF, quality of life, patient perspective

\section{Introduction}

The prevalence of diabetes mellitus (DM) in Australia is predicted to rise to $11.4 \%$ by 2025. ${ }^{1}$ A contemporary World Health Organisation report (2016) has projected that $8.5 \%$ of adults have DM globally. ${ }^{2}$ This is expected to correspond to a decline in quality of life (QoL), greater morbidity, and mounting economic health care utilisation. ${ }^{1,3,4}$

DM is associated with the risk of additional comorbidities, including ischemic heart disease, hypertension, hypercholesterolemia and chronic kidney disease, which may lead to additional complications, such as, peripheral neuropathy, dialysis and
Sydney Institute of Vision Science, Sydney

Retina Clinic, Level I3 I87 Macquarie

Street, Sydney 2000, NSW, Australia

Tel +6I 2 922I 3755

Fax +6I 292211637

Email achang@sydneyretina.com.au 
amputation. ${ }^{5}$ In addition, diabetic eye disease, more specifically diabetic retinopathy (DR) and diabetic macular oedema (DMO), may cause debilitating visual impairment and is one of the most prevalent causes of visual decline among diabetics. ${ }^{6}$ DMO is the consequence of chronic microvascular compromise and can develop by an inflammatory or ischemic mechanism. Elevated plasma glucose levels lead to weakening of the blood-retinal barrier through loss of pericytes. This inevitably leads to endothelial cell dysfunction and discharge of vascular endothelial growth factor (VEGF). ${ }^{7}$ Release of VEGF instigates capillary leakage, causing a collection of extracellular fluid at the macula. ${ }^{8,9}$ Additionally, VEGF triggers stimulation of inflammatory molecules and is associated with neuronal apoptosis and capillary non-perfusion. ${ }^{7}$

The first step in the treatment of DMO, as with DM, is to educate patients on lifestyle modifications such as diet and the systemic control of comorbidities, for instance, hypertension and hypercholesterolemia along with glucose levels. Previously, treatment for DMO involved the use of laser photocoagulation to lessen the chance of progression of DMO; however, patients had a low likelihood of visual improvement. ${ }^{10}$ Most recently, anti-VEGF therapies have revolutionised treatment of DMO. Numerous clinical trials have shown significant gains in visual acuity as well as a reduction in macular oedema. The DRCR.net protocol $\mathrm{T}$ study evaluated the efficacy of intravitreal Eylea, Avastin and Lucentis for DMO and observed a mean visual acuity improvement of 13 letters, 10 letters and 11 letters, respectively, with similar safety and side effect profiles. ${ }^{11}$ As DMO may show alteration from a VEGF-facilitated mechanism in the acute phases to an inflammatory mechanism in chronic cases, steroids have been shown to be another potential treatment, particularly in cases of refractory $\mathrm{DMO}^{7}$ Recently, Ozurdex, an injectable implant that allows a slow, sustained release of dexamethasone, has demonstrated effective results for up to 6 months. ${ }^{12,13}$ They can also work well in combination with other modalities such as laser and anti-VEGF, ${ }^{14}$ although the best potential patients for these are those with chronic DMO who have not responded to multiple laser therapy treatments and multiple anti-VEGF injections. ${ }^{15}$

DMO continues to develop as a global health care burden as the incidence of DMO and the costs of its treatment increase. There is a need to identify effective treatments. ${ }^{16}$ Current standard of care for DMO involves anti-VEGF therapy and intravitreal corticosteroids; ${ }^{17,18}$ unlike previous laser therapy, visual recovery is more likely. ${ }^{18}$ However, like DM, DMO cannot be cured only treated. Treatment is usually required monthly, imposing a significant burden on patients and their carers. ${ }^{8}$ Typically, each monthly visit requires comprehensive ophthalmic evaluation, including imaging by means of optical coherence tomography (OCT), fundoscopy and treatment in the form of intravitreal injections and more recently, intravitreally delivered slow-release corticosteroid implants. ${ }^{18}$ Additionally, fluorescein angiography may be performed for additional study of the circulation of the retina and choroid. ${ }^{19}$

The increasing number of therapeutic options and potential combination therapies for DMO raise significant questions about the costs of treating DMO. However, though the burden of treatment may increase, the benefits of them may be outweighed considering the maintenance of independence and quality of life. These costs are related to the expense of treatment, including health care provider services, imaging and medications. Although these direct medical costs are substantial, they must be considered in relation to the economic impact of DMO in terms of the non-treatment-related indirect costs of DMO and the lost productivity of individuals with DMO.

While the prevalence of those diagnosed with diabetes persists as a product of the increasing populace, increased in the elderly, obesity, and inactive standard of living, the burden of diabetic complications on health care systems, including DMO, is also expected to increase. ${ }^{20} \mathrm{DMO}$ affects over $15 \%$ of all diabetic adults in Australia, ${ }^{21}$ increasing to $21.9 \%$ among those with type $2 \mathrm{DM}$. DMO is debilitating as it may lead to continuing visual impairment, affecting function, independence and adversely influencing the quality of life. ${ }^{22}$ It is the most prominent origin of vision loss among working-aged Australians. Although DMO can involve all ages, its consequences can be distinctively different among differing age groups. Those employed persons with DMO may experience a loss in work production and permanence of employment, whilst those of retirement age may have a greater need for carer assistance and social isolation due to DMO.

Appreciating the multifaceted effects of DMO upon sufferers and their subsequent health care requirements is crucial for optimal management of their disease. Due to the ongoing advances in medical therapies for DMO, ongoing research is required to appreciate the experience and burden of treatment on patients and carers. Accordingly, this paper aims to examine the treatment burden of patients with DMO and their carers. 


\section{Methods}

This prospective observational, cross-sectional study enrolled participants drawn from a national online consumer panel and the New South Wales and Victorian Diabetes Foundations. Participants who were diagnosed with either type 1 or 2 diabetes and undergoing intravitreal treatment for macular oedema in one or both eyes were included. Patients required the capacity to impart informed consent and be able to complete an online questionnaire. Patients who had not had an intravitreal injection within the preceding 6 months were excluded.

The study was approved by Bellberry Limited institutional review board and was conducted according to the Declaration of Helsinki. All participants gave informed consent and concealment of all data was conserved.

The online questionnaire was designed as a collaboration between Allergan, Australia and So What Research. The survey included questions relating to 1) the impact of DMO and other related comorbidities on daily life; 2) management and treatment of DMO; 3) the emotional and physical impact of the injection experience and 4) identify potential improvements to treatment regimens. The data were collected and analysed by So What Research, Sydney, Australia. Patients were screened to ensure they had 1) been diagnosed with type 1 or $2 \mathrm{DM}$; 2) been diagnosed with DMO; 3) received injections for the treatment of their DMO and 4) recent intravitreal treatment for DMO within the past 6 months.

\section{Measures}

\section{Demographic And Health Characteristics}

Age, sex, marital status, and the presence of comorbidities were evaluated. These comorbidities were then applied to calculate the Charlson comorbidity index (CCI) score, which is a weighted index recognised to be prognostic of mortality. Every comorbidity is specified a grade, between 1 and 6 , to obtain an index score. Ahigher score designates a higher comorbidity burden.

\section{DM Type}

Participants were supplied with a register of health disorders, as well as the choice to select "type I" or "type 2 diabetes" and "if they had developed any problems with your eyes as a result of diabetes?" If the participant selected "Yes" they then qualify for the remainder of the survey relating to diabetic eye disease.

\section{Number Of Ocular Complications}

DM participants were then asked "Which of the following eye problems have you been diagnosed by a doctor?" with the option of selecting "diabetic macular oedema - blurred or distorted vision", "haemorrhages - loss of vision", "proliferative retinopathy", "detached retina", "cataract" and "dry eye". If participants selected "none of the above," they were then excluded from further analyses. Participants were then asked questions relating to treatment of their DMO.

\section{Health Care Utilisation}

This was classified as the quantity of health professional visits ("how many times have you seen each of the following health care providers for the management of your diabetes and associated DMO?) reported in the last 6 months, and "how long does each appointment take with each of the following health care professionals (including waiting time)?"

\section{Humanistic And Emotional Burden Of DMO Treatment}

This was assessed using a 13-item instrument relating to anxiety, impairment of daily activities and personal economic burden as a result of intravitreal treatment for DMO, and personal views of treatment delivery.

\section{Caregiver Burden}

This involved a series of questions relating to caregiver help received either directly or indirectly for the treatment of DMO.

\section{Statistical Analysis}

Parametric outcomeutcomes variables included age, gender, CCI score and diabetes-associated comorbidities and concomitant ophthalmic conditions. Categorical data were reported using frequencies and percentages. Statistical analyses were performed using Statistical Package for Social Sciences (SPSS) software (version 24.0, SPSS Inc., USA). Qualitative data were given as descriptive statistics.

\section{Results}

\section{Study Patients}

Sixty-five DMO patients completed the online survey involving participants from all states and territories across Australia, with $71 \%$ of patients living in a capital city or large metropolitan city. The median patient age was 52.5 years, showing a male predominance of $68 \%$. Forty-eight 
(74\%) of the participants had type 2 diabetes, and 17 (26\%) had type 1 diabetes, with 40 patients undergoing bilateral treatment for DMO. Demographics of included patients are presented in Table 1.

Among the 65 patients, $47.7 \%$ were employed full time and $24.6 \%$ were retirees. The participants stated they lived at home with their partner $(75 \%)$ and/or children $(30 \%)$ or alone (20\%). Almost $50 \%$ of the patients had received their last injection within the past 1 month of completing the online survey, whilst $37 \%$ had an injection within the past 2-3 months, showing that the impact of DMO reported in this study is based on relatively recent experiences.

\section{Ocular And Systemic Comorbidities}

Working-aged diabetic participants ( $\leq 55$ years) with DMO had a substantially greater diabetes-associated comorbidity burden than those aged $>55(\mathrm{p}=0.05)$. A substantial proportion of patients had the expected comorbidities of hypertension, dyslipidemia and heart disease, with a significantly high CCI of 2.7 among the entire cohort (Table 2). Whilst 31 (48\%) of the participants also stated they had depression or anxiety. Participants with three or more comorbidities also stated a substantially lengthier time since diagnosis compared to those with one comorbidity. Many also had concomitant ocular pathology being glaucoma (22\%), dry eye (39\%) and cataract (31\%) (Table 3). A further five participants stated they had had a previous retinal detachment.

\section{Emotional Impact}

Patients stated their diabetes had a moderate-to-large impact on their daily lives. Equally significant was the impact of DMO, with $69 \%$ of patients considering their condition as serious and $78 \%$ reporting that they think about it at least once a week, if not daily. Forty-five per cent of patients stated that living with macular oedema impacted their ability to work, $48 \%$ stated it affected the kind of work they can do and less freedom to decide their employment situation and $36 \%$ stated it affected the amount of time they were able to work in a week. DM participants reported significant overall work productivity loss and impairment in daily activities. These carried over to less prospects in regard to developing new skills, less provision of assistance and acknowledgement and reservations that perhaps their health status may constrain their capacity to work until retirement age. Those with three or

Table I Demographics Of Included Patients

\begin{tabular}{|c|c|c|}
\hline Age, years & & 52.5 \\
\hline \multirow[t]{4}{*}{ GENDER } & Male, $n(\%)$ & $44(67.7)$ \\
\hline & Female, n (\%) & $21(32.3)$ \\
\hline & Type I diabetes, n (\%) & $17(26.2)$ \\
\hline & Type 2 diabetes, $\mathrm{n}(\%)$ & $48(73.8)$ \\
\hline \multirow[t]{7}{*}{ EMPLOYMENT } & Working full time, n (\%) & $31(47.7)$ \\
\hline & Retired, n (\%) & $16(24.6)$ \\
\hline & Working part-time, n (\%) & $12(18.5)$ \\
\hline & Disability pensioner, $\mathrm{n}(\%)$ & $3(4.6)$ \\
\hline & Currently looking for work, n (\%) & $\mathrm{I}(\mathrm{l} .5)$ \\
\hline & Homemaker, n (\%) & $\mathrm{I}(\mathrm{l} .5)$ \\
\hline & Student, n (\%) & $\mathrm{I}(\mathrm{I} .5)$ \\
\hline \multirow[t]{6}{*}{ AREA } & Capital city/other metropolitan city (population of $100,000+$ ), n (\%) & $46(70.8)$ \\
\hline & Regional city (population of 25,000 to 100,000 ), $n$ (\%) & $14(2 \mid .5)$ \\
\hline & Regional/rural area (population $<25,000$ ) & $4(6.2)$ \\
\hline & - next larger city more than $100 \mathrm{~km}$ away, $\mathrm{n}(\%)$ & \\
\hline & Regional/rural area (population $<25,000$ ) & $\mathrm{I}(\mathrm{I} .5)$ \\
\hline & - next larger city within 100 km radius, n (\%) & \\
\hline \multirow[t]{5}{*}{ WHO LIVES IN HOUSEHOLD } & My partner, n (\%) & $49(75.4)$ \\
\hline & My children, n (\%) & $20(30.8)$ \\
\hline & I live on my own, n (\%) & $13(20.0)$ \\
\hline & Other family members, $\mathrm{n}(\%)$ & $4(6.2)$ \\
\hline & My parents, n (\%) & $2(3.1)$ \\
\hline
\end{tabular}


Table 2 Systemic Comorbidities

\begin{tabular}{|l|l|}
\hline Hypertension, n (\%) & $29(44.6)$ \\
Hypercholesterolemia, n (\%) & $29(44.6)$ \\
Heart disease, n (\%) & II (I6.9) \\
Arthritis, n (\%) & $20(30.7)$ \\
Depression or anxiety, n (\%) & $31(47.7)$ \\
Migraine, n (\%) & $23(35.5)$ \\
Asthma, n (\%) & $17(26.2)$ \\
Cancer, n (\%) & $6(9.2)$ \\
Cerebrovascular attack, n (\%) & $5(7.7)$ \\
Thyroid cndition, n (\%) & $5(7.7)$ \\
COPD, n (\%) & I (I.5) \\
\hline
\end{tabular}

more comorbidities reported greater work productivity loss, and activity impairment, than those with one comorbidity.

A significant proportion of patients $(48 \%)$ stated that living with DMO affected their emotional well-being, their ability to drive (39\%) and their dependence on others for daily activities such as personal care, bathing, eating and dressing (25\%),

High levels of anxiety ("score 8-10" out of 10) featured in $67 \%$ of patients for their first injection, it still affected $52 \%$ of patients even after two or more injections. However, the patients felt that this may be alleviated by educating patients more about the procedure. While the entry of the needle into the eye to inject the drug was identified as the treatment aspect causing the most anxiety, the time spent in the waiting room and the travel to the surgery rank higher than the preparation for the injection (Figure 1). Fifty-eight $(86 \%)$ of patients had a caregiver accompany them into the clinic, and $58 \%$ of all patients receive some form of help from caregivers. Of those requiring carer assistance, $72 \%$ stated they felt guilt for asking their carer for assistance. This anxiety led 54\% of patients reporting disturbed sleep due to overwhelming thoughts about an upcoming injection.
Patients overwhelming wanted the injection experience to improve ( $\mathrm{n}=95 \%)$. Patients stated this would be ideally by fewer injections (48\%) and appointments (91\%), and more reimbursements available of the costs for supplementary tests $(86 \%)$, such as optical coherence tomography (OCT) imaging. Reducing the waiting times before the procedure as well as having more information were also considered priorities by most patients $(75 \%)$.

\section{Health Care Utilisation}

The management of their conditions with different health care providers (HCP) placed a significant burden on patients (Table 4), with the visits to ophthalmologists adding to this burden particularly due to their frequency and length. The average DMO patient reported seeing a mean of four different HCPs over a mean $12.5 \mathrm{HCP}$ visits within the past 6 months, specifically for the management of diabetes and associated DMO, taking up a mean of $12 \mathrm{hrs}$ for the HCP appointments over a 6-month period (excluding travel). On average, 84 mins was spent at an ophthalmologist appointment. In addition to the $1.5 \mathrm{hrs}$ required for each injection appointment, participants spent another hour travelling to and from the appointment, predominately by car. Employed patients reported taking a mean of 2 days off work for the treatment and recovery afterwards. DMO patients had undergone a mean of seven intravitreal injections. Fifty per cent of those patients receiving bilateral treatment were administered on separate days. Ultimately, appraisals of health care resource consumption increased among those with a greater Charlson comorbidity score. The most prevalent variances were for those participants with three or more comorbidities, where their group resource utilisation was significantly greater than other participants.

\section{Caregiver Burden}

The majority of caregivers, $86 \%$, offer informal primary care, with the mean time devoted to caregiving being $5.61 \pm 7.7 \mathrm{hrs}$ per week. Furthermore, the mean time employed caregivers

Table 3 Ophthalmic Comorbidities

\begin{tabular}{|c|c|c|}
\hline EYE PROBLEMS DIAGNOSED BY A DOCTOR & $\begin{array}{l}\text { Diabetic macular oedema, n (\%) } \\
\text { Dry eye, n (\%) } \\
\text { Cataract, n (\%) } \\
\text { Proliferative retinopathy, n (\%) } \\
\text { Glaucoma, n (\%) } \\
\text { Haemorrhages, n (\%) } \\
\text { Detached retina, n (\%) }\end{array}$ & $\begin{array}{l}65(100.0) \\
25(38.5) \\
20(30.8) \\
16(24.6) \\
14(21.5) \\
10(15.4) \\
5(7.7)\end{array}$ \\
\hline TREATMENTS RECEIVED FOR DIABETIC MACULAR OEDEMA & $\begin{array}{l}\text { Intravitreal Injections, n (\%) } \\
\text { Laser treatment, n (\%) }\end{array}$ & $\begin{array}{l}65(100.0) \\
21(32.3)\end{array}$ \\
\hline
\end{tabular}




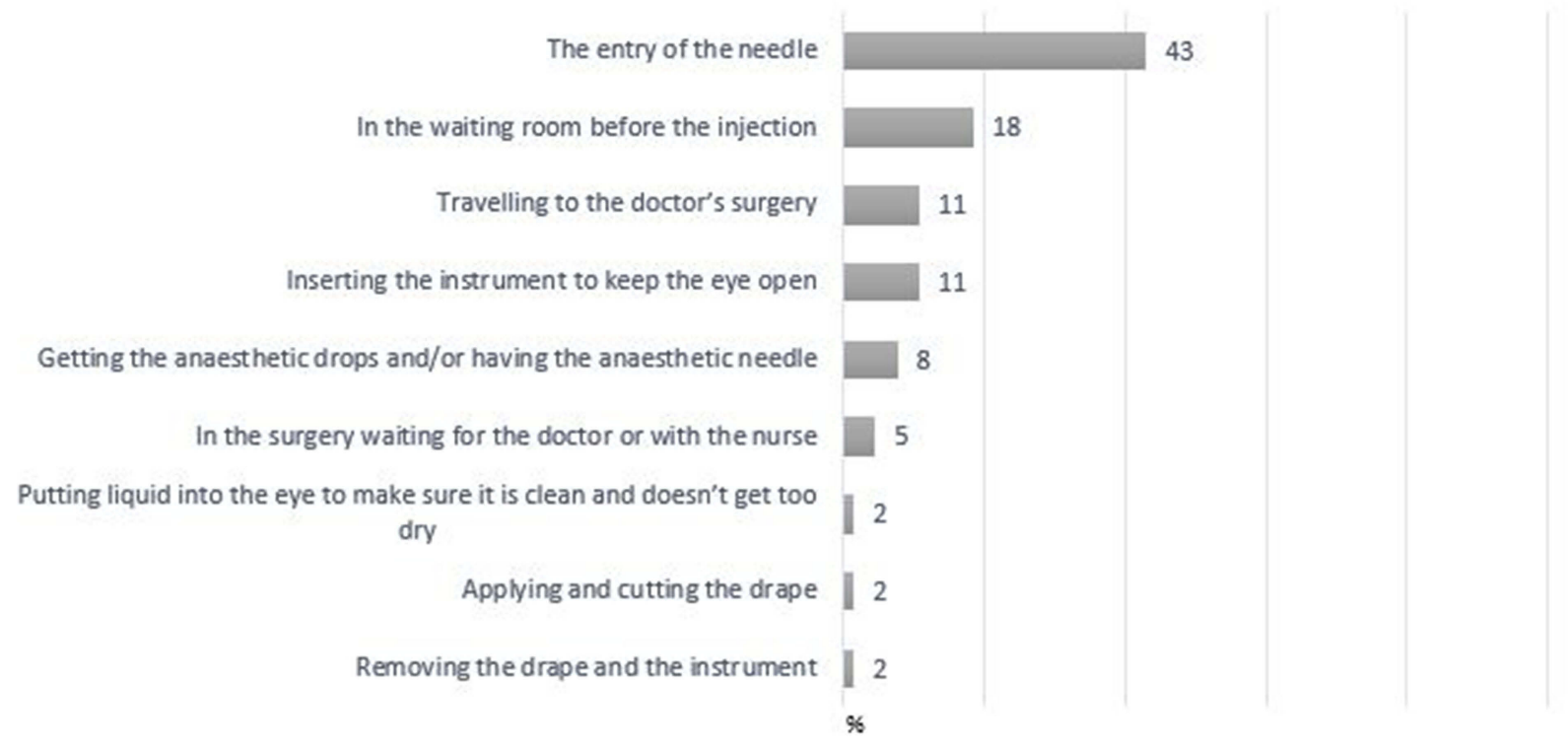

Figure I Unprompted responses of 65 participants on what is the most anxious aspect of their treatment for diabetic macular oedema (DMO).

Table 4 Health Care Providers (HCPs) Seen For Management Of Their Diabetes

\begin{tabular}{|l|l|l|}
\hline HCP & Mean Visits Over 6 Months, (SD) & Mean Time At Appointment, mins (SD) \\
\hline General practitioner (GP) & $4.2(2.5)$ & $40(35)$ \\
Ophthalmologist & $3.9(2.5)$ & $84(56.25)$ \\
Optometrist & $1.4(1.25)$ & $45(29.25)$ \\
Diabetic nurse/diabetes educator & $3.0(4.0)$ & $46(27.5)$ \\
Dietitian/nutritionist & $1.7(1.5)$ & $51(26.25)$ \\
Podiatrist & $3.6(2.25)$ & $33(10)$ \\
Nurse at GP clinic & $3.4(4.0)$ & $31(16.25)$ \\
Cardiologist & $1.3(1.25)$ & $50(27.5)$ \\
Nephrologist & $1.9(0.5)$ & $51(25.0)$ \\
Neurologist & $2.0(0.5)$ & $76(32.5)$ \\
Other & $10.5(4.75)$ & $45(7.5)$ \\
\hline
\end{tabular}

were absent from work due to this assistance was $3.9 \pm 1.75$ hrs each appointment. The predicted mean annual hours necessitated for caregiving were $46.8 \pm 21 \mathrm{hrs}$ for all caregivers and $42.5 \pm 18.7 \mathrm{hrs}$ for employed and 51.1 $\pm 23.2 \mathrm{hrs}$ for those caregivers not currently employed. Most of the cost to the caregivers was related with escorting participants to health care provider visits. The caregivers spent on average $3.9 \mathrm{hrs}$ helping a patient, and $50 \%$ needed to take time off work in order to do so.

Most caregivers (89\%) accompanied participants during $90-100 \%$ of HCP visits, with most caregivers $(67 \%)$ also remaining with the participant during the visit. The mean time spent accompanying patient at each visit was $234.0 \pm 420.0 \mathrm{mins}$ and the mean annual time spent escorting patients to hospital visits was $97.5 \pm 175.5 \mathrm{hrs}$.

\section{Discussion}

The aim of this study was to evaluate the economic and humanistic burden of DMO in a patient population where the principal therapy was intravitreal anti-VEGF therapy. The present study supplements the current published data by appraising the comorbidity outline and resource utilisation of those with DMO based on recent data from a nationally representative dataset of diabetic adults. Disease burden is essential in understanding a patient's apprehensions, to improve and address compliance with anti-VEGF therapy.

Treatment and follow-up of DMO patients are contingent on the mechanism causing the DMO, the patient's response to treatment and the duration of treatment, which varies between patients. The location and pattern of DMO may alter the management and prognosis among patients. 
A considerable decline in a patient's vision at initial presentation, along with other comorbidities and treatment side effects, must also be considered in the management plan. The burden of treatment in chronic disease produces challenges in compliance and adherence to treatment, as seen in those with macular degeneration. ${ }^{23,24}$ Patients with DMO and their carers experience considerable treatment burden from multiple intravitreal injections. It has been reported that patients with numerous injection appointments have an amplified risk of non-compliance to therapies they find burdensome. ${ }^{25}$ The principal findings include a considerably greater incidence of diabetes-associated comorbidities and greater health care resource utilization among DMO patients, which increased with the number of comorbidities. The prevalence of cardiovascular and renal disease was higher among this cohort, despite the mean age being near to 50 years. From the present study, it is clear that diabetic patients have multiple health care providers involved in their care, from general practitioners to endocrinologists, dietitians and neurologists. ${ }^{5}$ Attending multiple visits has a significant impact on their daily commitments and quality of life. ${ }^{12,26}$ The present findings are comparable to those described in similar research. ${ }^{12,26}$ A previous analysis using a comparable methodology similarly reported that working-age DMO patients had significantly more comorbidities than non-DMO patients. ${ }^{27}$

The burden of DMO treatment is not only confined to the patient, but also carers, being predominately family and friends, and the wider community due to the high economic impact of this disease. ${ }^{3}$ The patients reported the main cost component was loss of income and the burden on the carer. Several factors contribute to the costs of diabetes, including the costs to the health care system, out-of-pocket expenses for the individual patient and their carers and community resources. ${ }^{3}$ The total annual cost for people with diabetes in Australia was estimated to be $\$ 2.2$ billion, increasing to $\$ 3.1$ billion when the costs of carers were included. ${ }^{28}$ This leads to high health care resource utilisation by diabetic patients, as they have a tendency to utilise health care resources such as health care visits, prescription medications, sick leave and worker's compensation. ${ }^{3}$ The patients reported a mean of 12.5 hrs per month spent on appointments, accumulating to $150 \mathrm{hrs}$ annually. This clear appointment burden demonstrates the extra visits required of those with diabetes due to their numerous comorbidities, ${ }^{28}$ with $48 \%$ of patients having multiple comorbidities.
This study confirms that diabetes has a more pronounced effect on a patients' QoL. ${ }^{29}$ The results from this research confirm those from several studies that have evidently demonstrated the emotional and functional impact that DMO places on these patients. ${ }^{30-32}$ The burden increases as the vision deteriorates. A reduced QoL can impede how a patient can manage their disease, potentially exacerbating their diabetes and inducing additional difficulties. ${ }^{33}$

A reduction in the injection frequency could diminish the burden of therapy and optimise patient disease management by fostering compliance. Patient responses visibly indicated that $95 \%$ felt lessening the frequency of appointments and injections for the equivalent visual effects is thought to be the greatest critical amendment to treatment burden, thus reducing their anxiety. As DMO patients have a significant health care burden, it is imperative to take into account the intensity of treatment when deciding on DMO treatment. Extra health provider appointments could not only cause distress to those with DMO, but similarly caregivers and other health care providers of comorbidities who may be accountable for the management of several HCP appointments. ${ }^{7}$ More recently, studies have described that patient compliance with treatment may not be as regular as directed by current management standards established by clinical trial data, impinging results. ${ }^{21,34-36}$

In understanding the outcomes of the present study, it is essential to recognise the limitations of this study. The small sample size included somewhat younger DMO patients, which may not be representative of the diabetic population. Moreover, the questionnaire was presented that relied on the participant's ability to recollect and consequently subject to recall bias. Additionally, the information was gathered by means of an online questionnaire. Consequently, it was not possible to obtain visual acuity or ocular anatomical data which may have affected the regularity of DMO appointments. Moreover, potential participants with lower visual acuity may not be encapsulated as those with lower functional vision would impact upon their capability to participate in the questionnaire.

This research identifies the comprehensive influences that treatment burden has on patients with DMO. Moderating the burden of HCP visits, delivering improved education and the provision of assistance for those with DMO would reassure patients undergoing intravitreal injections. This research provides additional considerations for health care providers when deciding on a course 
of treatment. Management of DMO with reduced treatments and appointments may aid in lowering the potential burden to patients as too their dependence on their caregivers and health care resource utilisation. Furthermore, decreased occurrence of injections may also lessen the economic burden and assist in decreasing the effect on health care resources. This will be an important consideration as the prevalence of diabetes rises.

\section{Ethical approval}

All procedures performed were in accordance with the ethical standards of the institutional research committee and with the 1964 Helsinki declaration and its later amendments or comparable ethical standards. Informed consent was obtained from all individual participants included in the study. Ethics approval was granted from Bellberry Limited, Australia, on 14 November 2018. Application number: 2018-09-745.

\section{Acknowledgments}

The authors would like to acknowledge and thank, Jodi Tainton from Allergan, Australia, for her help in initiating the project.

\section{Author contributions}

G.G. and S.K. developed the methods, conducted the study, extracted data and performed the analyses and revised the manuscript. K.S. wrote the draft manuscript and performed additional analyses, additional data extraction and interpretation of data. T.H. reviewed and edited the analyses and interpretation of data and revised and edited the manuscript. A.C. conceived the idea, edited and revised the manuscript, supervised the findings of this work and oversaw responsibility of the data. All authors discussed the results and contributed to and approved the final manuscript. All authors agree to be accountable for all aspects of the work ensuring that questions relating to the accuracy or integrity of all the work are appropriately investigated and resolved.

\section{Disclosure}

Andrew A Chang has acted as a consultant for Novartis, Bayer and Alcon. Gerry Guinan and Saskia Koller are employees of So What Research, Australia Pty Ltd. Gerry Guinan reports personal fees from Allergan Australia Pty Ltd, during the conduct of the study; personal fees from Allergan Australia Pty Ltd, outside the submitted work; Saskia Koller reports personal fees from Allergan, during the conduct of the study. The authors report no other conflicts of interest in this work.

\section{References}

1. Magliano DJ, Shaw JE, Shortreed SM, et al. Lifetime risk and projected population prevalence of diabetes. Diabetologia. 2008;51 (12):2179-2186. doi:10.1007/s00125-008-1150-5

2. World Health Organisation. Global Report On Diabetes. Published April 2016.

3. Schofield D, Cunich MM, Shrestha RN, et al. The economic impact of diabetes through lost labour force participation on individuals and government: evidence from a microsimulation model. BMC Public Health. 2014;14:220. doi:10.1186/1471-2458-14-220

4. Wallick CJ, Hansen RN, Campbell J, Kiss S, Kowalski JW, Sullivan SD. Comorbidity and health care resource use among commercially insured non-elderly patients with diabetic macular edema. Ophthalmic Surg Lasers Imaging Retina. 2015;46(7):744-751. doi:10.3928/23 258160-20150730-09

5. Farrell C, Moran J. Comparison of comorbidities in patients with prediabetes to those with diabetes mellitus type 2. Ir Med J. 2014;107 (3):72-74

6. Liew G, Michaelides M, Bunce C. A comparison of the causes of blindness certifications in England and Wales in working age adults (16-64 years), 1999-2000 with 2009-2010. BMJ Open. 2014;4(2): e004015. doi:10.1136/bmjopen-2013-004015

7. Bahrami B, Zhu M, Hong T, Chang A. Diabetic macular oedema: pathophysiology, management challenges and treatment resistance. Diabetologia. 2016;59(8):1594-1608. doi:10.1007/s00125-0163974-8

8. Bahrami B, Hong T, Gilles MC, Chang A. Anti-VEGF therapy for diabetic eye diseases. Asia Pac J Ophthalmol (Phila). 2017;6(6):535545. doi:10.22608/APO.2017350

9. Lally DR, Shah CP, Heier JS. Vascular endothelial growth factor and diabetic macular edema. Surv Ophthalmol. 2016;61(6):759-768. doi:10.1016/j.survophthal.2016.03.010

10. Lim LT, Chia SN, Ah-Kee EY, Chew N, Gupta M. Advances in the management of diabetic macular oedema based on evidence from the diabetic retinopathy clinical research network. Singapore Med J. 2015;56(5):237-247. doi:10.11622/smedj.2015071

11. Wells JA, Glassman AR, Ayala AR, et al. Aflibercept, bevacizumab, or ranibizumab for diabetic macular edema: two-year results from a comparative effectiveness randomized clinical trial. Ophthalmology. 2016;123(6):1351-1359. doi:10.1016/j.ophtha.2016.02.022

12. Aroney C, Fraser-Bell S, Lamoureux EL, Gillies MC, Lim LL, Fenwick EK. Vision-related quality of life outcomes in the BEVORDEX study: a clinical trial comparing ozurdex sustained release dexamethasone intravitreal implant and bevacizumab treatment for diabetic macular edema. Invest Ophthalmol Vis Sci. 2016;57 (13):5541-5546. doi:10.1167/iovs.16-19729

13. Boyer DS, Yoon YH, Belfort R Jr., et al. Three-year, randomized, sham-controlled trial of dexamethasone intravitreal implant in patients with diabetic macular edema. Ophthalmology. 2014;121 (10):1904-1914. doi:10.1016/j.ophtha.2014.04.024

14. Hussain RM, Ciulla TA. Treatment strategies for refractory diabetic macular edema: switching anti-VEGF treatments, adopting corticosteroid-based treatments, and combination therapy. Expert Opin Biol Ther. 2016;16(3):365-374. doi:10.1517/14712598.2016.1131265

15. Pacella F, Romano MR, Turchetti P, et al. An eighteen-month followup study on the effects of intravitreal dexamethasone implant in diabetic macular edema refractory to anti-VEGF therapy. Int $J$ Ophthalmol. 2016;9(10):1427-1432. doi:10.18240/ijo.2016.10.10

16. Pershing S, Enns EA, Matesic B, Owens DK, Goldhaber-Fiebert JD. Cost-effectiveness of treatment of diabetic macular edema. Ann Intern Med. 2014;160(1):18-29. doi:10.7326/M13-0768 
17. Abraham NG, Srinivasan K, Thomas J. Normative data for near point of convergence, accommodation, and phoria. Oman J Ophthalmol. 2015;8(1):14-18. doi:10.4103/0974-620X.149856

18. Bucolo C, Gozzo L, Longo L, Mansueto S, Vitale DC, Drago F. Long-term efficacy and safety profile of multiple injections of intravitreal dexamethasone implant to manage diabetic macular edema: A systematic review of real-world studies. J Pharmacol Sci. 2018;138 (4):219-232. doi:10.1016/j.jphs.2018.11.001

19. Couturier A, Rey PA, Erginay A, et al. Widefield OCT-angiography and fluorescein angiography assessments of nonperfusion in diabetic retinopathy and edema treated with anti-vascular endothelial growth factor. Ophthalmology. 2019. doi:10.1016/j.ophtha.2019.06.022.

20. Williams R, Airey M, Baxter H, Forrester J, Kennedy-Martin T, Girach A. Epidemiology of diabetic retinopathy and macular oedema: a systematic review. Eye (Lond). 2004;18(10):963-983. doi:10.1038/ sj.eye. 6701476

21. Tapp RJ, Shaw JE, Harper CA, et al. The prevalence of and factors associated with diabetic retinopathy in the Australian population. Diabetes Care. 2003;26(6):1731-1737. doi:10.2337/diacare.26.6.1731

22. Gonder JR, Walker VM, Barbeau M, et al. Costs and quality of life in diabetic macular edema: Canadian burden of diabetic macular edema observational study (C-REALITY). J Ophthalmol. 2014;2014:939315. doi:10.1155/2014/939315

23. Spooner KL, Mhlanga CT, Hong TH, Broadhead GK, Chang AA. The burden of neovascular age-related macular degeneration: a patient's perspective. Clin Ophthalmol. 2018;12:2483-2491. doi:10. 2147/OPTH.S185052

24. Vaze A, Fraser-Bell S, Gillies M. Consequences of long-term discontinuation of vascular endothelial growth factor inhibitor therapy in the patients with neovascular age-related macular degeneration. Acta Ophthalmol (Copenh). 2014;92(8):e697-e698. doi:10.1111/aos.12417

25. Polonsky WH, Henry RR. Poor medication adherence in type 2 diabetes: recognizing the scope of the problem and its key contributors. Patient Prefer Adherence. 2016;10:1299-1307. doi:10.2147/PPA.S106821

26. Suner IJ, Bressler NM, Varma R, Dolan CM, Ward J, Turpcu A. RESPONSIVENESS OF THE NATIONAL EYE INSTITUTE VISUAL FUNCTION QUESTIONNAIRE-25 TO VISUAL ACUITY GAINS IN PATIENTS WITH DIABETIC MACULAR EDEMA: evidence from the RIDE and RISE trials. Retina (Philadelphia, Pa). 2017;37(6):1126-1133. doi:10.1097/IAE.0000000000001316
27. Hanemoto T, Hikichi Y, Kikuchi N, Kozawa T. The impact of different anti-vascular endothelial growth factor treatment regimens on reducing burden for caregivers and patients with wet age-related macular degeneration in a single-center real-world Japanese setting. PLoS One. 2017;12(12):e0189035. doi:10.1371/journal.pone.0189035

28. Lee CM, Colagiuri R, Magliano DJ, et al. The cost of diabetes in adults in Australia. Diabetes Res Clin Pract. 2013;99(3):385-390. doi:10.1016/j.diabres.2012.12.002

29. Megari K. Quality of life in chronic disease patients. Health Psychol Res. 2013;1(3):e27. doi:10.4081/hpr.2013.932

30. Granstrom T, Forsman H, Leksell J, Jani S, Raghib AM, Granstam E. Visual functioning and health-related quality of life in diabetic patients about to undergo anti-vascular endothelial growth factor treatment for sight-threatening macular edema. J Diabetes Complications. 2015;29 (8):1183-1190. doi:10.1016/j.jdiacomp.2015.07.026

31. Okamoto Y, Okamoto F, Hiraoka T, Oshika T. Vision-related quality of life and visual function following intravitreal bevacizumab injection for persistent diabetic macular edema after vitrectomy. Jpn J Ophthalmol. 2014;58(4):369-374. doi:10.1007/s10384-014-0323-7

32. Turkoglu EB, Celik E, Aksoy N, Bursali O, Ucak T, Alagoz G. Changes in vision related quality of life in patients with diabetic macular edema: ranibizumab or laser treatment? J Diabetes Complications. 2015;29 (4):540-543. doi:10.1016/j.jdiacomp.2015.03.009

33. Fritschi C, Quinn L. Fatigue in patients with diabetes: a review. $J$ Psychosom Res. 2010;69(1):33-41. doi:10.1016/j.jpsychores.2010.01. 021

34. Polat $\mathrm{O}$, Inan $\mathrm{S}$, Ozcan $\mathrm{S}$, et al. Factors affecting compliance to intravitreal anti-vascular endothelial growth factor therapy in patients with age-related macular degeneration. Turk J Ophthalmol. 2017;47 (4):205-210. doi:10.4274/tjo.28003

35. Stewart MW. Individualized treatment of neovascular age-related macular degeneration: what are patients gaining? Or losing? J Clin Med. 2015;4(5):1079-1101. doi:10.3390/jcm4051079

36. Gupta OP, Shienbaum G, Patel AH, Fecarotta C, Kaiser RS, Regillo CD. A treat and extend regimen using ranibizumab for neovascular age-related macular degeneration clinical and economic impact. Ophthalmology. 2010;117(11):2134-2140. doi:10.1016/j.ophtha.2010.02.032

Diabetes, Metabolic Syndrome and Obesity: Targets and Therapy

Dovepress

Publish your work in this journal

Diabetes, Metabolic Syndrome and Obesity: Targets and Therapy is an international, peer-reviewed open-access journal committed to the rapid publication of the latest laboratory and clinical findings in the fields of diabetes, metabolic syndrome and obesity research. Original research, review, case reports, hypothesis formation, expert opinion and commentaries are all considered for publication. The manuscript management system is completely online and includes a very quick and fair peer-review system, which is all easy to use. Visit http://www.dovepress.com/testimonials.php to read real quotes from published authors. 